\title{
Associative versus motivational interpretations of reward percentage effects on children's performance
}

DAVID R. PEDERSON

UNIVERSITY OF WESTERN ONTARIO

Forty children received a black or a white marble following each of 41 lever pulling responses. Reward percentage was manipulated by instructing $S s$ in a 50 percent reward condition that marbles of only one color could be accumulated toward a prize. Marbles of both colors could be collected toward a prize in a 100 percent reward condition. The findings showed that, contrary to an associative hypothesis, Ss in the 50 percent reward condition moved the lever faster than did Ss receiving 100 percent reward.

Many recent experiments have shown that children perform an instrumental response with greater speed if this response is partially, rather than continuously, rewarded (Bruning, 1964; Ryan, 1966; Ryan \& Moffitt, 1966). Two hypotheses have been suggested to account for these results. Amsel (1958) and Spence (1960) have assumed that an aversive motivational condition, which they term frustration, is produced in circumstances in which $\mathrm{S}$ anticipates but does not receive reward. The resultant increment in motivation is taken to be the factor leading to faster asymptotic performance associated with partial reward. Brown (1961) and Marx (1956) have suggested than an associative mechanism, rather than a motivational one, may account for the above results. They assume that, in the past. Ss may have been reinforced for making more vigorous responses in the face of nonreward. In studies with children, the partial reward operation differed from continuous reward only in that the mechanism dispensing the reward was disengaged on the nonrewarded trials. This associative interpretation would indicate that the more vigorous responding found for partial reward may have been elicited by the inoperative reward dispenser. Such an effect could be mediated by implicit verbal responses of the nature "marbles (rewards) get stuck sometimes." The faster response speeds may then be attributed to the child's attempts to jar the marbles loose by forceful manipulation of the response lever.

The present study was an attempt to evaluate these two alternative explanations. An implication of this associative interpretation is that if nonreward were manipulated in a manner unlikely to indicate a malfunctioning apparatus, there should be no speed differences between partially and continuously rewarded groups. In the present study, nonreward was indicated by the marble color, rather than by witholding of the reward object.

\section{Method}

The Ss were 20 male and 20 female children, obtained from the Cedar Rapids Community School District, ranging in age from 5 years 10 months to 7 years 6 months with a mean age of 6 years 11 months.

Each $\mathrm{S}$ was conducted individually to the experimental room where he was shown a lever apparatus and told that he would have an opportunity to win a prize by playing a marble game. The $S$ was instructed to put his hand on a red hand patterm and to pull the lever when a red light surrounding a vertical excursion channel was illuminated. For all Ss, 50 percent of the lever responses were followed by an ejection of a black marble; the remaining responses were followed by ejection of a white marble. The Ss in the continuously rewarded group (Group 100) were informed that both the black and the white marbles could be accumulated towards the prize. Only one color marble (either black or white) counted towards the prize for $S s$ in the partial reward group (Group 50). The marble color designated as counting for Group 50 or appearing on corresponding trials for Group 100 was counterbalanced so that each percentage of reward group was further divided into two subgroups $\mathrm{B}_{+}$or $\mathrm{W}_{+}$. Ten Ss were randomly assigned to each of the resulting four experimental groups: $100 \mathrm{~B}+$, $100 \mathrm{~W}_{+}, 50 \mathrm{~B}+$, and $50 \mathrm{~W}_{+}$.

All Ss received one rewarded practice and 40 training trials at the rate of one every $20 \mathrm{sec}$. The same marble color sequence was used for all Ss. This sequence was random with the restriction that four marbles of each color were dispensed in each block of eight trials. The $E$ initiated a trial by the use of a verbal "ready" signal and by pressing a button that activated a Hunter Klockounter and illuminated the red stimulus light. Movement of the lever $1 / 8$ in. from its resting position stopped the Klockounter and activated a Standard Precision Timer. At a point $10 \mathrm{in}$. from the beginning of its excursion, the lever crossed a photobeam which stopped the Standard Timer and started a Hunter Decade Interval Timer. The Interval Timer activated one of two solenoids that released either a black or a white marble into a box directly below the end of the excursion channel. The time recorded from the Klockounter was recorded as starting time and that from the Standard Timer as movement time. 


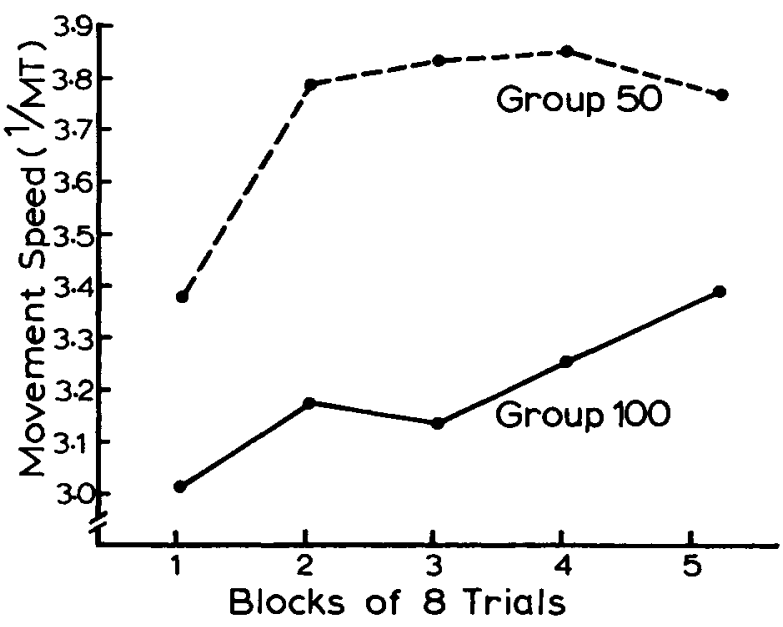

Fig. 1. Mean movement speeds for each reward percentage group as a function of trial blocks, averaged over counterbalancing conditions.

\section{Results and Discussion}

Figure 1 presents the movement speed trial block means (reciprocals of the movement time scores) for Group 100 and Group 50 averaged over counterbalancing conditions. A Lindquist (1953) Type III mixed design analysis of variance was conducted on the movement speed data. The between-Ss effects were percentage of reward (Group 100 vs. Group 50) and counterbalancing conditions (Group B+ vs. Group W+). The within-Ss effect was five blocks of eight trials. The analysis revealed that the main effects for reward percentage $(F=4.78, d f=1 / 36, p<.05)$ and for trial blocks $(F=6.94, \mathrm{df}=4 / 144, \mathrm{p}<.01)$ were significant. Counterbalancing conditions entered into no significant effects in this analysis. A second Lindquist (1953) Type III analysis was conducted on the starting speed data (reciprocals of the starting time scores). Although a similar relationship between Group 50 and Group 100 was observed in the starting speed data, interactions involving counterbalancing conditions made the reward percentage effects less clear-cut than in the movement speed analysis.

The finding of faster movement speeds for Group 50 as compared with those for Group 100 is consistent with the results of similar comparisons in studies conducted by Bruning (1964), Ryan (1966), and Ryan \& Moffitt (1966). This finding is also in agreement with the hypothesis that nonreward leads to an increment in motivation as suggested by the frustration formulation of Amsel (1958) and Spence (1960).
Since a marble was dispensed on each trial, the associative interpretation outlined earlier suggests that there should be no difference between the partial and continuous reward groups in the present study. The finding of faster movement speeds for Group 50 casts doubt on the tenability of this hypothests. Other assoclative hypotheses could be proposed to account for the influence of partial reinforcement on response speeds. For example, nonreward may have elicited the assumption that performance has been inadequate. On future trials, Ss may have tried harder by responding more vigorously in an attempt to obtain rewards consistently.

Finally, a comment should be made concerning the performance of Group 100 across trial blocks. In previous studies (e.g., Bruning, 1964; Ryan, 1966), performance under 100 percent reward has been relatively constant across trials; in the present study, response speeds showed a general increase. The uncertainty about the color of the next marble may have made the task more interesting for $\mathrm{Ss}$ in the present study than for Ss in previous studies using the same reinforcement on every trial.

\section{References}

Amsel, A. The role of frustrative nonreward in noncontinuous reward situations. Psychol. Bull., 1958, 55, 102-119.

Brown, J. S. The motivation of behavior. New York: McGraw-Hill, 1961.

Bruning, J. L. The effects of magnitude of reward and percentage of reinforcement on a lever movement response. Child Develpm., $1964,35,281-285$.

Lindquist, E. F. Design and analysis of experiments in psychology and education. Boston: Houghton Mifflin, 1953.

Marx, M. H. Some relations between frustration and drive. In M. R. Jones (Ed.), Nebraska symposium on motivation. Lincoln: University of Nebraska Press, 1956.

Ryan, T. J. Instrumental performance as related to several reward schedules and age. J. exp. child Psychol., 1966, 3, 398-404.

Ryan, T. J., \& Moffitt, A. R. Response speed as a function of age, incentive value, and reinforcement schedule. Child Develpm., 1966, 37, 103-113.

Spence, K. W. Behavior theory and learning. Englewood Cliffs, New Jersey: Prentice-Hall, 1960.

\section{Note}

1. This report is based on a thesis submitted in partial fulfillment of the requirements for the $M$. A. degree in the Institute of Child Behavior and Development at the University of Iowa. The author gratefully acknowledges his indebtedness to Gordon N. Cantor, under whose direction the research was conducted. Appreciation is also expressed to the following individuals in the Cedar Rapids Community School District for their cooperation: A. W. Salisbury, Superintendent; ira Semler, Research Director; and Catherine Eckstein, Principal of the Cleveland Elementary School. 